\title{
Construcións de infinitivo con referencia persoal no iberorrománico
}

\author{
Infinitive Constructions with Personal Reference \\ in Ibero-romance
}

\author{
BEgoña URUBuru RoDríGUEZ \\ bego.uruburu@gmail.com \\ Recibido: diciembre 2015. Aceptado: febrero 2016
}

Resumo: No presente artigo, tentaremos comparar as construcións de infinitivo nas distintas linguas do eido iberorrománico, haxa ou non haxa un infinitivo flexionado en cada lingua, para dilucidar, na medida en que sexa posíbel, como todas as linguas iberorrománicas si posúen un infinitivo persoal, a pesar deste non ser flexionado ou conxugado. Para iso, analizaremos unha serie de exemplos obtidos de distintos textos literarios, para o galego; xornalísticos, para o portugués; de carácter científico, no caso do mirandés e do asturo-leonés antigo.

Palabras chave: infinitivo conxugado, infinitivo persoal, iberorrománico, correferencialidade.

\begin{abstract}
In this paper, we are going to compare infinitive constructions in some Iberian-Romance languages, whether or not there is an inflected infinitive in each language, in order to find out, as far as we can, that all Iberian-Romance languages do have a personal infinitive, although this is not inflected. For that reason, we are going to analyse a number of examples from different literary texts, in the case of Galician; newspaper articles, for Portuguese; and scientific texts, with respect to Mirandese and old Asturian-Leonese.
\end{abstract}

Key Words: inflected infinitive, personal infinitive, Iberian-Romance, correferenciality.

\section{INTRODUCIÓN}

Pretendemos estudar no presente traballo un fenómeno gramatical concreto: as construcións de infinitivo con referencia persoal no ámbito das linguas ibe- 
rorrománicas. Cando falamos de construcións de infinitivo con referencia persoal, referímonos tanto ás construcións en que aparece un infinitivo conxugado (caso dalgunhas linguas iberorrománicas), como aqueloutras construcións en que, a pesar de non aparecer ou non existir un infinitivo conxugado no sistema da lingua, o infinitivo forma unha oración e posúe un suxeito e, daquela, unha referencia persoal. $\mathrm{O}$ diasistema lingüístico galego-portugués, o mirandés e, fóra da Romania, o sardo logudorés, contan no seu sistema gramatical cun infinitivo conxugado, o cal ofrece morfemas flexivos de persoa e número. Ao longo da historia dos estudos románicos, tense ofrecido distintas hipóteses para tratar de explicar a orixe desta peculiar forma. Sexa como for, nós centraremos a nosa exposición en tentar comparar as construcións de infinitivo nas distintas linguas do ámbito iberorrománico, haxa ou non haxa un infinitivo flexionado en cada lingua concreta, para dilucidar como todas as linguas románicas si posúen un infinitivo persoal, a pesar de non ser conxugado ou flexionado. Deste modo, empregaremos a nomenclatura de infinitivo flexionado ou conxugado cando falemos do infinitivo que presenta marcas flexivas de persoa e número nas linguas devanditas, e infinitivo persoal, para falarmos do infinitivo non flexionado que apareza en construcións con referencia persoal, ora nas linguas que non posúen un infinitivo flexionado, ora naquelas que, a pesar de si o teren, non o empregan en determinadas construcións.

\section{O INFINITIVO NO ÁMBITO ÍBERO-ROMÁNICO}

O infinitivo (cantar), o xerundio (cantando) e o participio (cantado) denomínanse formas non persoais do verbo. Teñen sido chamadas tamén formas non finitas, non flexionadas, non flexivas, non conxugadas, derivados verbais e verboides (NGLE 2009: 1961).

As marcas formais que caracterizan o infinitivo, o xerundio e o participio nas linguas iberorrománicas son, respectivamente, $-r,-n d o$ y $-d-o(-d-a /-d-o-s$ / $-d-a-s)$, precedidas pola vogal temática propia de cada unha das conxugacións: cant-a-r, cant-a-ndo, cant-a-d-o (ou cant-a-d-a, cant-a-d-o-s, cant-a-d-a-s). Vemos, pois, que as tres formas non persoais do verbo posúen marcas ou afixos flexivos, aínda que carezan da flexión de persoa-número ${ }^{1}$, de tempo e de modo, propia das demais formas verbais.

Desde os primeiros estudos gramaticais sobre as linguas románicas, tense abordado a complexidade que mostran as construcións con infinitivo. É ben sabido que a dita complexidade radica na dobre natureza, nominal e verbal, do infinitivo, o que conduciu os gramáticos xustamente a unha dobre visión destas construcións. Por un lado, hai quen pon de relevo o carácter nominal do infinitivo, e, polo outro, están aqueles que teñen salientado o seu carácter verbal.

Para alén diso, é moi importante levar en conta desde un primeiro momento que, como xa anunciabamos na introdución, nalgunhas linguas do ámbito ibe-

${ }^{1}$ Como veremos ao longo da nosa exposición, o infinitivo flexionado ou conxugado é unha forma verbal moi viva nalgunhas linguas románicas (sobre todo en portugués). 
rorrománico, como son o galego-portugués e o mirandés, tamén existe un infinitivo flexionado (IF), que si ofrece marcas de persoa e de número, o cal coidamos que achega esta categoría máis do verbo do que do substantivo.

$\mathrm{O}$ infinitivo é fundamentalmente verbo e, daquela, núcleo do SV, aparecendo neutralizadas nel todas as categorías do verbo (excepto ás veces a persoa e o número), ben porque hai outros elementos na oración que as expresan, ou porque non é necesario indicalas. Igual que a oración con verbo finito, a oración con infinitivo pode levar complementos (Freixeiro Mato 2006: 376):

(1) a. GL. Para facermos esa viaxe, cómpre aforrarmos moitos cartos.

b. PT. Para fazermos essa viagem, cúmpre aforrarmos moito dinheiro.

c. ES. Para hacer ese viaje, tenemos que ahorrar mucho dinero.

Fóra dos casos da substantivación, o infinitivo é normalmente verbo nuclear dunha oración inserida, ou ben subordinada, nas linguas iberorrománicas, intercambiábel pola forma finita (Convén chegarmos cedo / Convén que cheguemos cedo). A oración dependente nucleada polo infinitivo, frecuentemente coa súa forma flexionada en galego-portugués, pode desempeñar todas as funcións do substantivo.

No que se refire ao castelán, a RAE, na súa Nueva gramática de la lengua española (2009), afirma que o infinitivo ten sido considerado na tradición gramatical como unha categoría híbrida, dado que ofrece ao mesmo tempo propiedades nominais e verbais. Ora ben, na obra magna da lingua castelá, tamén se di que, aínda que se adoite aceptar que os infinitivos do español poden ser verbais ou nominais, algúns infinitivos manifestan excepcionalmente propiedades que pertencen a ambos os grupos ao mesmo tempo. Na maioría dos casos, os infinitivos poden ser empregados nuns contextos ou noutros, que se diferencian tanto na súa sintaxe, como no seu significado (NGLE 2009: 26.2a 1963).

\section{CONSTRUCIÓNS DE INFINITIVO CON REFERENCIA PERSOAL EN GALEGO-PORTUGUÉS}

O galego-portugués é o diasistema máis occidental das linguas iberorromances, falado en toda a faixa occidental da Península, incluíndo Galiza e Portugal. Componse de dous paralectos, o galego e o portugués, lingua unitaria até aproximadamente o século XIII en que, por razóns históricas, ambas as variantes seguiron camiños distintos. O ámbito territorial do galego abarca Galiza, a zona máis occidental de Asturias entre os ríos Eo e Navia, o Baixo Bierzo, en León, e a comarca de As Portelas, en Zamora. Segundo algúns autores, a fala das tres vilas de Cáceres, Valverde, San Martín de Trebello e As Ellas, tamén incluiríase no ámbito galego (Frías Conde 1999). O portugués, polo seu lado, fálase en Portugal e en varias localidades españolas fronteirizas, como Olivenza (Olivença), en Badajoz; Herrera de Alcántara e Cedillo (Ferreira de Alcântara e Cedilho), en Cáceres; e Alamedilla (Alamedilha), en Salamanca. Ademais, en Portugal fálase un dialecto asturo-leonés na Terra de Miranda e, no sur, na loca- 
lidade de Barrancos, emprégase un dialecto portugués meridional con influencias andaluzas (Frías Conde 2013a: 18-19).

\subsection{Oracións inseridas co verbo en infinitivo en galego}

A oración inserida co verbo en infinitivo pode desempeñar en galego as seguintes funcións:

a) Suxeito:

(2) Pero vestir así ou doutra maneira tanto me ten (Neira Vilas Memorias dun neno labrego).

No exemplo proposto, as construción de infinitivo constitúe unha oración inserida (tradicionalmente clasificada como substantiva) con función suxeito do predicado principal (ten). Ao se tratar neste caso dunha 1. ${ }^{a}$ persoa do singular, é imposíbel dilucidar se estamos perante a forma flexionada ou a non flexionada do infinitivo, xa que, nestes casos, a desinencia do infinitivo flexionado sería Ø. Así e todo, a referencia persoal do infinitivo, asegúrase pola súa correferencia semántica co obxecto indirecto do predicado principal: (tanto) me (ten), é dicir, eu.

Nos casos en que o infinitivo aparece na súa forma non flexionada, a pesar de que pareza non posuír unha referencia persoal, o suxeito pódese deducir por outros medios, non gramaticais, mais si semánticos ou pragmáticos. O lector, ou o ouvinte, nunha situación comunicativa determinada, terá a información necesaria para dilucidar a quen tanto lle ten vestir así ou doutro xeito. Isto levaríanos a concluír, nun primeiro momento, que, nos casos en que o galego emprega o infinitivo flexionado, sexan precisamente motivacións semánticas ou pragmáticas, e non de índole gramatical, as que provoquen a aparición da forma flexionada. $\mathrm{O}$ falante sentiría a necesidade de facer máis explícito o suxeito do infinitivo e, para iso, flexionaría esta forma verbal. Esta afirmación poría en dúbida algunhas das explicacións que se ten dado sobre a orixe do infinitivo flexionado ou conxugado.

\section{b) Obxecto directo:}

(3) As cousas requiren ter o seu comenzo (Blanco Amor A Esmorga).

A oración inserida (tamén encadrada, segundo as teorías tradicionais, dentro das substantivas) coa función obxecto directo do predicado principal (requiren) está representada por unha construción de infinitivo, concertado, non flexionado. Así, a referencia persoal do infinitivo vén determinada polo feito de o suxeito deste ser o mesmo que o suxeito da oración principal, as cousas, representando, xa que logo, o que se coñece como infinitivo concertado. 
c) Obxecto preposicional ou rexido:

(4) Conservaba a vitalidade invasora que nos obrigaba a todos, xa de nenos, a facer sempre o que el quería (Casares $O$ sol do verán).

Neste exemplo, é posíbel observarmos unha construción de infinitivo que representa unha oración inserida nun predicado verbal e con función sintáctica de obxecto rexido. A construción de infinitivo atópase, polo seu lado, dentro dunha oración inserida de relativo, que funciona como complemento do sintagma nominal a vitalidade invasora (... a vitalidade invasora que nos obrigaba a todos, xa de nenos, a facer sempre o que el quería). O infinitivo facer é o núcleo predicativo da proposición que desempeña a función de obxecto rexido e a súa referencia persoal baséase no feito de coincidiren os referentes semánticos do seu suxeito (o do infinitivo), que permanece implícito ou cuberto, e do clítico nos, máis do grupo preposicional a todos, que funciona como obxecto directo do núcleo predicativo obrigaba.

\section{d) Complemento do nome:}

(5) Fixen a promesa de fuxir para sempre da casa (Neira Vilas Memorias dun neno labrego).

No anterior exemplo, a oración inserida, (de) fuxir para sempre da casa, aparece indicada pola preposición de e complementa o nome promesa. A pesar de aparecer un infinitivo non flexionado, a referencia persoal deste obtense pola desinencia verbal de 1 a $^{\mathrm{a}}$ persoa do singular que mostra o verbo principal, fixen e, daquela, polo contexto.

\subsection{Oracións subordinadas co verbo en infinitivo en galego}

As construcións de infinitivo poden constituír tamén en galego oracións subordinadas, cuxos subtipos máis salientábeis pasamos a concretar e analizar a seguir:

a) Con valor final:

(6) A Subela tenme dito moitas vegadas que todo é ensiño da nai pra me amolecer (Blanco Amor A Esmorga).

No exemplo que ofrecemos, a construción de infinitivo constitúe unha oración subordinada (clasificada tradicionalmente dentro do grupo das adverbiais) con valor final, indicada pola preposición para. Agora ben, a oración subordinada atópase dentro dunha estrutura oracional inserida, introducida pola conxunción que e con función obxecto directo do verbo principal, tenme dito. Neste caso, a referencia persoal do infinitivo asegúrase pola correferencialidade que representa o feito de que a referencia semántica do atributo da estrutura oracional da que depende a construción de infinitivo, ensiño da nai, sexa a mesma que a referencia semántica do suxeito do infinitivo. 
b) Con valor temporal:

(7) Dempois de teren pasado as cousas que soen pasar, levabamos máis dun mes sen o adubío (Blanco Amor A Esmorga).

Neste exemplo, a oración subordinada con valor temporal aparece indicada polo sintema conxuntivo dempois de. Neste caso, o infinitivo aparece flexionado na súa forma de 3 . $^{\text {a }}$ persoa do plural; ademais, o suxeito do dito infinitivo está aberto ou explícito, as cousas que soen pasar.

c) Con valor causal:

(8) Os clientes, xa for por experimentar de verdade, xa for por quereren brincar un bocadiño, deitábanse nas camas (Frías Conde FT).

No exemplo (8), as dúas construcións de infinitivo representan oracións subordinadas con valor causal, indicada pola preposición por. Chama a atención o feito de que, no primeiro caso, o infinitivo, experimentar, estea non flexionado, posibelmente debido á distancia dos dous infinitivos do suxeito, mentres que, no segundo, apareza unha forma flexionada, quereren. Sexa como for, as referencias persoais de ambos os dous infinitivos veñen determinadas ou aludidas polo suxeito da oración principal, os clientes, cuxa referencia é a mesma que a dos suxeitos das dúas oracións dependentes, suxeitos que permanecen implícitos ou cubertos.

\section{d) Con valor modal:}

(9) Os policías ficaran asombrados, sen comprenderen (Frías Conde FT).

A construción de infinitivo constitúe unha oración subordinada con valor modal, indicada pola preposición sen. A desinencia do infinitivo e o contexto reforzan a correferencialidade, que, neste caso, consiste en que coinciden os suxeitos da oración principal e da dependente, Os policías. Ademais, o participio asombrados, flexionado na forma masculina de plural, tamén asegura o recoñecemento da referencia persoal do infinitivo, xa que concerta en xénero e número co suxeito principal e dependente.

e) Con valor concesivo:

(10) ... xa me foi imposíbel, malia este ser o meu lar (Frías Conde $O$ caso máis estraño...).

En (10) a construción de infinitivo representa unha oración subordinada con valor concesivo. Observamos tamén a presenza dun suxeito explícito ou aberto, este, en posición preverbal, o cal resulta moi significativo dun punto de vista 
semántico e pragmático, tendo en conta que o infinitivo non posúe marca específica de flexión na 3 . $^{\mathrm{a}}$ persoa do singular, ser.

f) Con valor condicional:

(11) De estar en condicións normais, teríame sorprendido entón polo seu interese en min (Frías Conde A Aldea).

A estrutura oracional que conforma o exemplo (11) está formada por unha oración principal, simple, e por unha oración subordinada con valor condicional que aparece indicada pola preposición de. O Núcleo Predicativo da oración subordinada é un infinitivo (estar) e a súa falta de flexión, ademais da ausencia dun suxeito explícito, fai que a referencia persoal teña que se obter por outros mecanismos, como o contexto. O suxeito do infinitivo fica implícito e a súa referencia semántica é a mesma cá que ten o suxeito da oración principal, e podería incluír tamén a outra persoa. Malia que este suxeito tampouco aparece explicitamente, a referencia persoal vén expresada polo pronome enclítico me, que forma parte dun verbo pronominal flexionado na 1. ${ }^{\mathrm{a}}$ persoa do singular.

\subsection{Oracións inseridas con verbo en infinitivo en portugués}

As construcións de infinitivo poden desempeñar en portugués as mesmas funcións que vimos de explicar para o galego, constituíndo oracións inseridas, ou ben subordinadas. No caso do portugués, obtemos os exemplos dunha obra deseñada para estudantes de portugués L2, cuxo autor, Hélder Júlio Ferreira, analizou unha serie de publicacións periódicas portuguesas, aparecidas ao longo do ano 2003 nalgúns dos xornais portugueses máis importantes. Cos artigos seleccionados, o autor procurou abranguer un abano o máis amplo posíbel da cultura e civilización portuguesas.

a) Suxeito ${ }^{2}$ :

(12) É impossível não sentirmos um arrepio ao pensarmos no que eles representam.

No exemplo presentado aparece unha construción de infinitivo que desempeña a función de suxeito dunha oración complexa, na que aparece, daquela, inserida. A flexión do infinitivo, sentirmos, respectivamente, amósase até certo punto necesaria para determinar cal é a referencia persoal do infinitivo. De non aparecer a flexión, o recoñecemento persoal do infinitivo quedaría supeditado ao contexto e a factores, daquela, semánticos e pragmáticos. Como viamos no caso do galego, o falante extraerá da situación comunicativa en que se atope en cada momento a información precisa para recoñecer o suxeito dos infinitivos que conforman as oracións inordinadas.

\footnotetext{
2 Exemplos tirados de Ferreira Montero, H. J. (2003).
} 
b) Obxecto directo:

(13) O Presidente pediu a todos para pro fazerem levantamentos sobre cada uma das áreas.

É destacábel o feito de que en portugués as construcións de infinitivo que representan unha oración inserida con función obxecto directo do verbo principal veñan introducidas pola conxunción completiva para, o cal non é propio do galego. No exemplo dado, para alén da flexión do infinitivo, a referencia persoal deste veríase reflectida no sintagma preposicional a todos, que funciona como obxecto indirecto do verbo principal, pediu, e cuxo referente coincide co do suxeito do infinitivo. A referencia semántica do pronome todos coincide coa referencia semántica do suxeito do infinitivo fazerem, suxeito que fica implícito ou oculto.

c) Obxecto preposicional ou rexido:

(14) O líder do PS acusou o Governo de ter conducido o país a mais pobreza e mais desigualdade.

En (14), non coinciden os referentes dos suxeitos do verbo principal ( $\mathrm{acu}$ sou) e o do infinitivo (ter conducido), o cal aparece na súa forma non flexionada. Así, a referencia persoal deste baséase noutros mecanismos de carácter contextual e pragmático: o referente semántico do suxeito do infinitivo, que está implícito, coincide co referente do sintagma o Governo, que funciona como obxecto directo dentro da oración principal, correferencialidade que axuda a detectar a referencia persoal do infinitivo non flexionado, mais si persoal.

d) Complemento do nome:

(15) Agora é o tempo de os filhos desempenharem as tarefas de que os pais vão necessitar.

No exemplo fornecido nesta ocasión, a construción de infinitivo representa unha oración inserida no predicado principal con función $\mathrm{CN}$, indicada pola preposición $d e$. Para alén de aparecer o infinitivo flexionado, aparece un suxeito externo, explícito, de maneira que a referencia persoal está dobremente expresada. A mera presenza dese suxeito externo serviría para asegurar o recoñecemento do referente semántico desta función, mais coidamos que as desinencias flexivas do infinitivo aportan aínda maior expresividade á oración global.

\subsection{Oracións subordinadas co verbo en infinitivo en portugués}

a) Con valor final:

(16) O marido quer a janela fechada para não se constiparem os dois. 
Neste exemplo, atopamos unha construción de infinitivo que funciona ou representa unha oración subordinada con valor final con respecto a un predicado principal, indicada pola preposición para. Ademais, para alén de aparecer o infinitivo flexionado (constiparem), aparece un suxeito explícito en posición postverbal, os dois. De non marcar mediante algúns destes dous mecanismos o referente persoal do infinitivo, a localización dos suxeitos, nestes casos, veríase dificultada, tendo en conta que no exemplo aportado non é posíbel recorrer ao mecanismo da correferencialidade.

\section{b) Con valor temporal:}

(17) A ideia não foi aprobada na conferencia porque, antes de os trabalhos parlamentares serem suspensos, no início do ano, havia já um texto redigido pela primeira comissão.

Nesta subsección, analizamos unha construción de infinitivo que representa unha oración subordinada con valor temporal. Dita oración está nucleada polo infinitivo serem, que aparece flexionado. Ademais, a súa referencia persoal refórzase pola presenza dun suxeito léxico, explícito (os trabalhos parlamentares), e pola flexión do participio suspensos, constituínte dunha forma verbal perifrástica.

\section{c) Con valor causal:}

(18) O responsável criticou os jornalistas por divulgarem a discrição do suspeito.

No exemplo (18), observamos unha construción de infinitivo que conforma unha oración subordinada con valor causal, indicada pola preposición por. A referencia persoal do infinitivo, divulgarem, vén dada pola flexión desta forma verbal, neste caso coa desinencia de 3 . $^{\text {a }}$ persoa do plural, e pola correferencialidade, consistente en que o referente semántico do suxeito, implícito, do infinitivo coincide co referente semántico do obxecto directo, os jornalistas, do verbo principal.

\section{d) Con valor modal:}

(19) Serena Williams conquistou o seu décimo título de um Grand Slam ao vencer pela quarta vez o Open de Australia.

En (19), a oración subordinada con valor modal aparece indicada polo sintema ao e co verbo en infinitivo. Ao se tratar dunha 3 . $^{\mathrm{a}}$ persoa do singular, non é posíbel decidir se estamos ante unha forma flexionada ou non flexionada, de xeito que teñamos que acudir ao contexto para dilucidar cal é a referencia persoal deste infinitivo. Así, grazas á presenza do suxeito da oración principal, Serena Williams, é doado recoñecer que o suxeito da oración dependente é o mesmo que o da principal e que fica implícito. 
e) Con valor concesivo:

(20) As pessoas querem novidade, a pesar decontinuarem a gostar dos clássicos.

En (20), a construción de infinitivo, que aparece flexionado, conforma unha oración subordinada con valor concesivo con respecto á oración principal. Dita oración (continuarem a gostar dos clássicos) aparece indicada polo sintema ou locución conxuntiva a pesar de. O infinitivo mostra as desinencias de 3. ${ }^{a}$ persoa do plural, de tal modo que é doado identificar a súa referencia persoal. Para alén diso, coinciden os referentes do suxeito da oración principal $\left(\right.$ As pessoas $\left.^{3}\right)$ e da oración dependente, onde permanece implícito.

\section{f) Con valor condicional:}

(21) No caso de os passageiros optarem por viajar num voo posterior, as transportadoras continuarão obrigadas a prestar-lhes assistência.

No exemplo (21), a construción de infinitivo constitúe unha oración subordinada con valor condicional con respecto á estrutura oracional principal, indicada polo sintema conxuntivo no caso de. Nesta oración, podemos observar, ademais dun suxeito externo, os passageiros, desinencias de persoa e número para o infinitivo, optarem.

\section{CONSTRUCIÓNS DE INFINITIVO CON REFERENCIA PERSOAL EN MIRANDÉS E EN ASTURO-LEONÉS ANTIGO}

Debido a que a literatura sobre o moderno mirandés e o asturo-leonés histórico é certamente limitada, a información referente ao uso do infinitivo flexionado nestas dúas variedades lingüísticas non é tan detallada como nas outras variedades románicas estudadas até aquí.

\subsection{Construcións de infinitivo con referencia persoal no mirandés}

Ofrecemos a seguir un exemplo do IF empregado polo mirandés ${ }^{4}$ :

(22) Ora stában alhi postas seis talhas de piedra, paraserbíren a las purificaçones (Monteiro, E. Reporter n. 1521), con valor final.

\footnotetext{
${ }^{3}$ Así e todo, este suxeito (As pessoas) parece ter un carácter impersoal, de xeito que, aínda que represente un suxeito desde o punto de vista sintáctico, a oración podería ser impersoal dun punto de vista semántico.

${ }^{4}$ Exemplo tirados de Scida, E. (2004), mais adaptamos a grafía mirandesa á escrita padrón desta lingua.
} 
No exemplo (22), a construción de infinitivo representa unha oración subordinada con valor final e aparece indicada pola preposición para. O infinitivo mostra a flexión de 3. ${ }^{\text {a }}$ persoa do plural, e o seu suxeito, que coincide co suxeito da oración principal, seis talhas de piedra, permanece implícito ou cuberto.

\subsection{Construcións de infinitivo con referencia persoal no asturo-leonés antigo}

O infinitivo flexionado tamén aparece no leonés antigo en textos do século XIII, procedentes de Sahagún e do Monasterio de San Andrés de Espinareda (Scida 2004: 139).

(23) Et si por aventura el Dean et el Cabildo non quisieren esto conprir heredes de dona Mayor meter capelan et pagarenlo de aquelas tiendas (Archivo Catedralicio y Diocesano de Salamanca, 246-247, 1253).

No exemplo (23), a construción de infinitivo conforma unha oración subordinada con valor condicional, indicada pola conxunción si. A referencia persoal do infinitivo baséase na flexión deste forma verbal, quisieren, e na presenza dun suxeito explícito ou aberto, el Dean et el Cabildo, que non coincide co suxeito da oración principal.

\section{CONSTRUCIÓNS DE INFINITIVO CON REFERENCIA PERSOAL EN CASTELÁN}

En castelán, o infinitivo flexionado ou conxugado non existe na actualidade, nin existiu en épocas pretéritas. Porén, isto non significa necesariamente que non existan nesta lingua construcións de infinitivo con referencia persoal ou mesmo o que chamariamos un infinitivo persoal. Por tanto, a inexistencia de desinencias no infinitivo español non supón que o infinitivo non teña un suxeito propio e, daquela, que non poida ser cualificado como persoal. En castelán, de feito, existen infinitivos persoais non flexionados ou conxugados, con suxeito propio, ora expreso, ora tácito. Vexamos, a seguir, algúns exemplos:

a) Infinitivos persoais con suxeito expreso:

(24) a. ES. Pese a estar enfermos sus padres, sus primos no fueron a visitarlos.

b. GL. A pesar de os seus pais estaren doentes, os seus curmáns non foron visitalos.

c. PT. Apesar de os seus pais estarem doentes, os seus primos não foram visitá-los. 
b) Infinitivos persoais con suxeito tácito:

(25) a. ES. El profesor les mandó responder a la pregunta.

b. GL. O profesor pediulles responderen á pregunta.

c. PT. O professor pediu-lhes para responderem à pergunta.

Fidalgo Enríquez (2011: 66) afirma existen tres aspectos fundamentais para estudar o infinitivo en castelán: a) Existencia de infinitivos persoais; b) Natureza categorial conflitiva do infinitivo; e c) Relacións de correferencialidade e dependencia gramatical. Como xa comprobamos nos exemplos devanditos, non existen no castelán infinitivos flexionados ou conxugados, mais si infinitivos persoais, non marcados mediante desinencias, senón a través dun suxeito expreso ou tácito. No que se refire á natureza categorial do infinitivo, afírmase a miúdo que este é ao mesmo tempo un substantivo verbal e un verbo nominal. Seguindo as palabras de Gutiérrez Araus (2004: 68): «esta forma verbal del español participa de una doble naturaleza: es verbo y es nombre, y de este hecho se derivan unas funciones peculiares que le dan cierta complejidad gramatical».

O infinitivo é unha categoría híbrida, mixta. Como núcleo dun predicado, pode levar complementos verbais, como un obxecto directo. Por outro lado, como nome, pode levar complementos nominais ou mesmo determinantes:

(26) a. ES. El recibir noticias de ellos fue agradable.

b. GL. O recibirmos noticias deles foi agradábel.

c. PT. Orecebermos notícias deles foi agradável.

Como se observa nestes exemplos, o infinitivo pode constituír unha oración inserida dentro dun período composto ou complexo, e realizar a función de suxeito do verbo principal. Mais, ao ser tamén unha forma verbal, precisa dun suxeito propio, quer expreso, quer tácito, para indicar os contidos de persoa e número. Normalmente, cando é núcleo dun predicado, depende argumentalmente doutra oración á que complementa. Estas relacións argumentais entre o verbo da oración principal e o verbo da oración inserida ou do verbo da subordinada, que pode ser un infinitivo, son denominadas nos estudos gramaticais relacións de correferencialidade. As correspondencias establécense entre os pronomes e os grupos nominais e son: «vínculos que permiten identificar los referentes de los primeros haciéndolos coincidir con los segundos» (NGLE2009: 1.31 13). Ademais, estas relacións poden ser anafóricas ou catafóricas, dependendo de se o sintagma nominal ou o pronome se refiren a un elemento anterior (antecedente) ou a un elemento posterior, respectivamente. Atendendo a esta correferencialidade, podemos falar de suxeitos tácitos e suxeitos expresos nas oracións inseridas que conteñen un infinitivo.

Os suxeitos tácitos son «elementos nulos o sobreentendidos, cuya interpretación se suele obtener por correferencia o identidad con otros sustantivos o grupos nomi- 
nales» (NGLE2009: 26.7b 1991). Estes suxeitos precisan dun elemento, antecedente ou referente, ao que aludir, que sería un suxeito correferente ou concertado.

Por outro lado, os suxeitos tácitos adoitan aparecer nas oracións nas que a dependencia gramatical é maior, como nas estruturas oracionais inseridas, tradicionalmente chamadas substantivas e adxectivas, cláusulas en que é doado recuperar o suxeito do infinitivo:

(27) Quiero ir contigo.

(28) Me ordenó hacer la cama.

No exemplo (27), a construción de infinitivo conforma unha oración inserida con función obxecto directo do verbo principal, quiero. Neste caso, os referentes das funcións suxeito da oración principal e da construción de infinitivo son o mesmo, de xeito que en castelán a única posibilidade que hai é empregar o que se coñece como infinitivo concertado ${ }^{5}$.

En (28), porén, sería posíbel empregar en castelán unha construción co verbo en forma finita, neste caso en pretérito de conxuntivo, por mor da consecutio temporum, xa que o verbo principal aparece en pretérito de indicativo. Así e todo, no exemplo que analizamos, atopamos unha construción de infinitivo, cuxa referencia persoal vén marcada polo contexto, xa que o referente da función obxecto indirecto $(m e)$ do verbo principal coincide co referente semántico dun suxeito tácito do infinitivo hacer.

É importante non falar de identidade de suxeitos entre a oración principal e a dependente como equivalente á correferencialidade, pois non sempre, nin obrigatoriamente, o suxeito da oración principal é o antecedente do suxeito da dependente. Pode mesmo, como vimos de observar, ser un obxecto directo ou un obxecto indirecto:

(29) a. ES. Mandé a los alumnos salir de clase (Antecedente obxecto indirecto).

b. GL. Mandei os alumnos saír / saírem de clase (Antecedente obxecto indirecto).

c. PT. Mandei os alunos sair / saírem das aulas (Antecedente obxecto indirecto).

No exemplo anterior, a construción de infinitivo, salir de clase, constitúe unha oración inserida substantiva con función obxecto directo do predicado principal, mandé. A correferencialidade, neste caso, consiste en que o referente semántico da función obxecto indirecto da oración principal, (a) los alumnos, coincide co referente semántico do suxeito tácito, implícito, do infinitivo. No caso do galego-portugués, a presenza do infinitivo flexionado parece que é

5 Non así en romanés, lingua en que, neste casos, se emprega o presente do conxuntivo: Vreau sămerg cu tine (= Quero ir contigo; literal: Eu quero que eu vaia contigo). 
opcional, pois se pode recuperar con facilidade o antecedente. Porén, nos casos nos que o antecedente non está claro, é preferíbel empregar o infinitivo flexionado. Coidamos, daquela, que a forma flexionada ou conxugada representa unha cuestión semántica, expresiva e, en definitiva, pragmática, que posúe o galego-portugués e da que carece o castelán.

Os suxeitos expresos, por outro lado, adoitan aparecer en castelán en oracións subordinadas -que complementan en bloque a estrutura oracional principal-, xa que non hai unha relación de dependencia gramatical cun elemento antecedente e é preciso marcar a diferenza de suxeitos mediante algunha forma gramatical:

(30) a. ES. Antes de llegar los ministros, ya conocíamos las noticias.

b. GL. Antes de os ministros chegaren, xa coñeciamos as noticias.

c. PT. Antes de os ministros chegarem, já conhecíamos as notícias.

Como podemos observar, atopamos neste exemplo unha oración subordinada con valor temporal, indicada polo sintema conxuntivo antes de. O verbo da oración dependente aparece na forma do infinitivo e a referencia persoal deste vén dada pola presenza dun suxeito expreso, que aparece posposto ao verbo dependente de forma obrigatoria. Así, sería agramatical unha construción como *Antes de los ministros llegar, onde parece que a preposición de rexeita a presenza dun suxeito preverbal. Ademais, o feito de que o referente da función suxeito do verbo principal non coincida co referente do suxeito do infinitivo favorece a presenza do suxeito léxico deste, co gallo de desfacer ambigüidades. O galego-portugués, por outro lado, non só pode delimitar o suxeito do infinitivo mediante as desinencias persoais, senón que tamén pode marcalo cun suxeito expreso, como fai o castelán. Nestes casos, falariamos dunha «dobre marcación» (Fidalgo Enríquez 2011: 68).

Do dito até aquí podemos extraer algunhas conclusións. Así, en castelán, non existe o infinitivo conxugado ou flexionado, mais si existe o infinitivo persoal. De feito, pódense constatar casos nos que o infinitivo parece ter un valor persoal sendo non conxugado. Para calquera análise dos infinitivos persoais e flexionados, tanto en galego-portugués, como en castelán, é indispensábel ter en conta as relacións de dependencia gramatical e, mais concretamente, as relacións de correferencialidade entre o elemento que funciona como suxeito do infinitivo e algún elemento que apareza dentro do predicado principal. Estas relacións parecen mostrar que os infinitivos posúen sempre suxeito, sexa tácito ou implícito, sexa expreso. Podemos verificar que o infinitivo flexionado ou conxugado en galego-portugués se constitúe en ocasións coma a marca propia constante do suxeito do infinitivo, mentres que o castelán non posúe marca propia de maneira constante. Así e todo, tanto o galego-portugués, canto o castelán, sérvense en ocasións doutras marcas que delimitan o suxeito dalgúns infinitivos, como acontece cos suxeitos expresos con pronomes ou grupos pronominais. Neste caso concreto, o galego-portugués duplicaría as marcas identificativas do suxeito do infinitivo mediante as desinencias verbais do infinitivo persoal e a través das outras marcas nominais. 
O infinitivo flexionado ten sido estudado nomeadamente desde unha abordaxe morfosintáctica, cando, na realidade, podemos observar que estamos perante un feito semántico e, sobre todo, pragmático. Todo acto de comunicación realízase nun contexto determinado e o uso do infinitivo persoal, como temos comprobado ao longo deste estudo, adoita estar motivado por razóns contextuais.

\section{CONCLUSIÓNS FINAIS}

Puidemos observar a cantidade de detalles que hai que ter en conta ao estudarmos o funcionamento das construcións de infinitivo con referencia persoal no eido iberorrománico.

Así, neste traballo tentamos estudar o funcionamento desta peculiar forma verbal, o infinitivo, nas linguas románicas que son faladas na Península Ibérica, ou ben foron faladas, como é o caso do asturo-leonés. A seguir, no que atinxe ao asunto fundamental que afrontamos aquí, explicamos as construcións que se atopan no ámbito lingüístico galego-portugués. Malia que temos separado os dous paralectos que conforman este diasistema lingüístico, é doado subliñar a cantidade de usos comúns que comparten o galego e o portugués. No caso concreto do infinitivo flexionado ou conxugado, é ben sabido que dita forma mostra un uso máis normal no portugués cotián do que no galego. Porén, o funcionamento das construcións de infinitivo con referencia persoal, estea flexionado ou non o estea, é practicamente idéntico en todo o ámbito galego-portugués.

No que atinxe ao diasistema asturo-leonés, que mostra algunhas formas flexionadas para o infinitivo en textos dos séculos XIII e XIV, é probábel que este fenómeno atope explicación nunha posíbel influencia da lingua galegoportuguesa, ou ben na espontaneidade propia do seu uso. Pasado o tempo, o asturo-leonés, fortemente modificado e reestruturado polo castelán, iría perdendo trazos que un día puideron ser característicos de seu. O infinitivo flexionado presente na lingua mirandesa, por outro lado, podería deberse a unha normal influencia da lingua portuguesa.

Tampouco deixamos de lado neste traballo a lingua castelá, na que, malia que non sexa posíbel atopar un infinitivo flexionado ou conxugado, si é doado observar distintos empregos de construcións de infinitivo equivalentes á oracións inseridas, ou ben subordinadas. Así, estas construcións aparecerán nucleadas precisamente polo infinitivo e terán, daquela, unha referencia persoal, que será o suxeito, implícito ou explícito, de dita forma verbal, e que poderá coincidir ou non co suxeito da oración principal.

\section{BIBLIOGRAFÍA DE REFERENCIA}

Cunha, C. e Cintra, L. (2009) Nova gramática do português contemporâneo, Lisboa, Edições João Sá da Costa. 
Egido Fernández, M. ${ }^{a}$ C. (1992) «Infinitivos conjugados en documentos leoneses del siglo XIII», Contextos, X/19-20, pp. 167-185.

Ferreiro, M. (1999) Gramática histórica galega. Fonética e Morfosintaxe, Santiago de Compostela, Laiovento.

Fidalgo Enríquez, F. J. (2012) «iInfinitivo personal en español?», Actas del IV Congreso sobre la enseñanza del español en Portugal. Évora, 2011, pp. 60-79.

Freixeiro Mato, X. R. (2006) Gramática da lingua galega II. Morfosintaxe, Vigo, A Nosa Terra.

Frías Conde, X. (1997) «Sobre os bloques dialectais do galego: unha nova proposta», Revista de Filología Románica, 14, pp. 241-256.

Frías Conde, X. (1999) O galego exterior às fronteiras administrativas, Gijón, VTP.

Frías Conde, X. (2013a) Introducción a la lingüística iberorrománica, Ocaña, Ianua Editora.

Frías Conde, X. (2013b) Compendio de Gramática Galega, Santiago de Compostela, Urco Editora.

Gargallo Gil, J. E. y Bastardas, M. ${ }^{a}$ R. (2007) Manual de lingüística románica, Barcelona: Ariel.

Gutiérrez Araus, M. ${ }^{a}$ L. (2004) Problemas fundamentales de la gramática del español como segunda lengua, Madrid: Arco/Libros.

Mattoso Câmara Jr., J. (1972) The Portuguese Language, Chicago, University of Chicago Press.

RAE (2009) Nueva gramática de la lengua española, Madrid, Espasa.

Scida, E. (2004) The Inflected Infinitive in Romance Language, New York, Routledge.

\section{Bibliografía das fontes literarias}

Campo Amor, E. (1970) A Esmorga, Edición de La Voz de Galicia (2001).

Casares, C. (2002) O sol do verán, Vigo, Editorial Galaxia.

Frías Conde, X. (2007) Inmolación Esférica, Pontevedra, El Taller del Poeta.

Frías Conde, X. (2009) Fique tranquilo, Pontevedra, El Taller del Poeta.

Frías Conde, X. (2012) A aldea, Compostela.

Neira Vilas, X. (1961) Memorias dun neno labrego, Edición de La Voz de Galicia (2002). 